\title{
EN BÚSQUEDA DE UNA INSERCIÓN FINANCIERA POSHEGEMÓNICA. LA POLIITICA FINANCIERA EXTERNA DEL KIRCHNERISMO*
}

\author{
Recibido: 05 de octubre de 2017 • Aprobado: 16 de marzo de 2018 \\ DOI: 10.22395/seec.v21n47a6
}

Pablo Nemiña**

\section{RESUMEN}

El artículo analiza las principales transformaciones acontecidas en la política financiera externa de Argentina entre 2003 y 2015. Con base en series estadísticas, fuentes periodísticas y bibliografía secundaria, se estudian las principales acciones del Estado en torno a la deuda pública externa, la estrategia de financiamiento y las relaciones con el sector financiero y los organismos internacionales de crédito. El desendeudamiento expresa el despliegue de una inserción financiera poshegemónica, caracterizada por apelar a recursos propios y al financiamiento externo de acreedores oficiales y multilaterales con los que había afinidad política. La aparición de la restricción externa generó un repliegue moderado en esta estrategia, que sufrió un giro drástico a partir del triunfo de la coalición Cambiemos.

\section{PALABRAS CLAVE}

Política financiera; deuda externa; finanzas internacionales; kirchnerismo; Argentina

\section{CLASIFICACIÓN JEL}

F34, F33, F02.

\section{CONTENIDO}

Introducción; 1. El giro neodesarrollista en la política exterior; 2. El canje de deuda y el pago al FMI; 3. El debate sobre el desendeudamiento; 4. Vivir con lo nuestro (y una ayudita externa). El impacto de la crisis financiera global; 5 . Regreso fallido a los mercados y la vía china; 6 . Reflexiones finales; Bibliografía

\footnotetext{
Con base en los hallazgos encontrados en un proyecto sobre la economía política de la relación entre el FMI y la Argentina, financiado por el Consejo Nacional de Investigaciones Científicas y Técnicas (Argentina), el presente artículo de investigación extiende y amplía el análisis hacia una economía política de las relaciones financieras internacionales de Argentina durante la posconvertibilidad. Se agradecen los comentarios de Alejandro Manzo y dos evaluadores a una versión preliminar. Naturalmente, se les exime de toda responsabilidad en cuanto a los errores $u$ omisiones existentes.

* Sociólogo, Universidad de Buenos Aires, Buenos Aires, Argentina. Doctor en Ciencias Sociales, Universidad de Buenos Aires, Buenos Aires, Argentina Investigador asistente del Consejo Nacional de Investigaciones Científicas y Técnicas, con sede en el Instituto de Altos Estudios Sociales de la Universidad Nacional de San Martín. Investigador Asociado del Área de Relaciones Internacionales, Facultad Latinoamericana de Ciencias Sociales, Buenos Aires, Argentina. Correo electrónico: pablonemina@yahoo.com.ar
} 


\title{
IN SEARCH OF A POSTHEGEMONIC FINANCIAL INCLUSION. THE EXTERNAL FINANCIAL POLICY OF KIRCHNERISM
}

\begin{abstract}
The paper analyzes the main transformations that occurred in the Argentine external financial policy between 2003 and 2015. Based on statistical series, journalistic sources, and secondary literature, the main actions of the State regarding external public debt, financing strategy and relations with the financial sector and international credit agencies are studied ."De-indebtedness" expresses the deployment of a posthegemonic financial inclusion, characterized by appealing to own resources and external financing from official and multilateral creditors with whom there was political affinity. The emergence of the external restriction caused a moderate retreat in this strategy, which underwent a drastic turnaround after the triumph of the "Cambiemos" coalition.
\end{abstract}

\section{KEYWORDS}

Financial policy; external debt; international finances; Kirchnerism; Argentina

\section{JEL CLASSIFICATION}

F34, F33, F02.

\section{EM BUSCA DE UMA INSERÇÃO FINANCEIRA PÓS-HEGEMÔNICA. A POLÍTICA FINANCEIRA EXTERNA DO KIRCHNERISMO}

\section{RESUMO}

O artigo analisa as principais transformações ocorridas na política financeira externa da Argentina entre 2003 e 2015. Com base em séries estatísticas, fontes jornalísticas e bibliografia secundária, são estudadas as principais ações do Estado em relação à dívida pública externa, a estratégia de financiamento e as relações com o setor financeiro e as agências internacionais de crédito. O desendividamento expressa a implantação de uma inserção financeira pós-hegemônica, caracterizada por apelar a recursos próprios e ao financiamento externo de credores oficiais e multilaterais com os quais havia afinidade política. O surgimento da restrição externa gerou um recuo moderado nessa estratégia, que sofreu uma drástica reviravolta depois do triunfo do movimento de coalizão Cambiemos.

\section{PALAVRAS-CHAVE}

Política financeira; dívida externa; finanças internacionais; kirchnerismo; Argentina.

\section{CLASSIFICAÇÃO JEL}

F34, F33, F02.

\section{CONTEÚDO}

Introdução; 1. Guinada neodesenvolvimentista na política exterior; 2. A conversão da dívida e o pagamento ao FMI; 3. Debate sobre a redução da dívida; 4. Viver com o nosso (e uma ajudinha externa). Impacto da crise financeira global; 5 . A falha no retorno aos mercados e o caminho chinês; 6. Reflexões finais; Bibliografia. 


\section{INTRODUCCIÓN}

Aunque el gobierno kirchnerista concluyó a finales de 2015, aún persisten varias controversias sobre el análisis de la gestión económica durante ese periodo. Mientras que autores liberales como Espert (2017) apuntan contra la decadencia que dejó el populismo, otros autores desde el marxismo, como Katz (2015), critican la tibieza de las reformas. Incluso entre las posiciones intermedias hay diferencias, que van desde el planteo de Aronskind (2015) de concebirla como el ejercicio de la soberanía posible ante los condicionamientos que impone la globalización, a una gestión que perdió la oportunidad histórica de poner al país en un sendero de desarrollo sostenible, como lo sostienen Damill y Frenkel (2013). De la autonomía periférica a "chocar la calesita".

Habida cuenta de las limitaciones que conllevan los análisis de largos periodos, queremos resaltar el contrapunto entre estas dos últimas miradas en torno a la interpretación que proponen sobre el rol que jugó la economía internacional. Si los primeros centran la atención en las restricciones estructurales que afectan a las economías periféricas, los segundos sugieren que el aumento de los precios de las materias primas generó condiciones suficientes para superar esos obstáculos. La inserción económica internacional a comienzos del siglo xxi aparece, entonces, como restricción o habilitación al desarrollo.

La respuesta a ese interrogante obliga a pensar en sectores económicos. En el caso de la integración comercial, los beneficios iniciales de los altos precios de las materias primas fueron opacados hacia el último lustro del periodo por el aumento de las importaciones de manufacturas y energía, que según Gaggero, Schorr y Wainer (2014), revirtieron el superávit comercial y ahondaron la restricción externa. Además, buena parte de la exportación de oleaginosas y minerales está en manos de empresas multinacionales, por lo cual muchas de las divisas obtenidas en el comercio se perdían como remisión de utilidades.

En oposición a lo anterior, la esfera financiera es quizá el sector en el cual Argentina mostró mayores márgenes de autonomía. La cesación de pagos declarada a finales de 2001, lo mismo que las duras renegociaciones de deuda que llevó adelante el kirchnerismo, redujeron los compromisos financieros externos y liberaron recursos fiscales para promover la actividad económica. Por otra parte, hasta finales del primer mandato de Cristina Fernández de Kirchner, el superávit de la cuenta corriente permitió implementar un proceso de desendeudamiento externo que incluyó el pago adelantado de la deuda al FMI, por casi diez mil millones de dólares.

En relación con lo anterior, autores como Alonso (2016) señalan que la Argentina estuvo "desconectada" de las finanzas internacionales. Si bien durante el periodo 
analizado el país realizó muy pocas emisiones de deuda en mercados internacionales, ello no significa que el vínculo con las instituciones y mercados financieros estuviera suspendido. En efecto, el gobierno llevó adelante dos reestructuraciones voluntarias de deuda que permitieron canjear casi el $93 \%$ de los títulos defaulteados en 2001; mientras que en la región acompañó la potenciación de la Corporación Andina de Fomento (CAF) como el Banco de Desarrollo de América Latina, que aumentó significativamente su financiamiento al país, y alentó la creación de nuevas instituciones financieras como el Banco del Sur, el cual entró en operaciones de forma tardía, en 2016, debido a las desavenencias entre Brasil y Venezuela. En el plano global, la administración aprovechó su silla en el G20 para promover de manera activa la agenda de reformas de los países en desarrollo para la gobernanza financiera internacional; asimismo, cuando se acentuó la caída de las reservas durante el segundo mandato de Cristina Fernández de Kirchner, el gobierno promovió una política de acercamiento paulatino a los mercados privados de deuda; pero la decisión de la Corte Suprema estadounidense de dejar firme el fallo favorable a los fondos buitres obturó ese camino y alentó la búsqueda de financiamiento en China.

Así entonces, se propone que, debido a los condicionamientos impuestos por el default al comienzo y al final del periodo (este último resultado del fallo del juez Griesa en relación al reclamo de los holdouts), y también por decisión política, la política financiera del país se caracterizó por el despliegue de una inserción financiera poshegemónica, con el fin de evitar las clásicas condicionalidades ortodoxas que reclaman el sector financiero internacional y los organismos multilaterales con sede en Washington, y explorar mayores márgenes de autonomía financiera.

El presente artículo analiza las principales transformaciones acontecidas en la política financiera externa de Argentina durante el periodo 2003-2015. Con base en series estadísticas oficiales, fuentes periodísticas y bibliografía secundaria, se estudian las principales acciones del Estado orientadas a enfrentar la problemática de la deuda pública externa, los cambios en la estrategia de financiamiento y las relaciones establecidas con el sector financiero y los organismos internacionales de crédito. La presentación, articulada según un orden cronológico, se divide en tres subperiodos que coinciden con diferentes etapas en la estrategia financiera: a), los años comprendidos entre 2003 y 2007, en los cuales, en el marco de un crecimiento acelerado, se realizó la primera reestructuración de deuda privada, se canceló la deuda con el FMI y se avanzó en la integración financiera regional; b), el periodo 2008-2013, en el cual, ante el estallido de las crisis financiera, el gobierno lanzó el segundo canje de deuda y combinó el financiamiento oficial externo con el uso de los recursos del Banco Central; y c), la etapa 2013-2015, en la que, luego de un acercamiento fallido a los mercados internacionales de capital, se recurrió al 
En búsqueda de una inserción financiera poshegemónica. La políica financiera externa del kirchnerismo

financiamiento de China para evitar aceptar los condicionamientos que imponía el fallo de Griesa. En la sección final, se hace una breve referencia al escenario abierto a partir triunfo de la Coalición Cambiemos.

\section{EL GIRO NEODESARROLLISTA EN LA POLÍTICA EXTERIOR}

De acuerdo con Ocampo (2011), en los primeros años del siglo xxi los países de América Latina y el Caribe se vieron beneficiados por un auge económico, alentado por una combinación inusual de factores externos. El acelerado crecimiento de las economías asiáticas, liderado principalmente por China, aumentó la demanda de recursos naturales, lo que conllevó un alza en los precios de las exportaciones latinoamericanas. Por otra parte, la baja de la tasa de interés promovida por EE. UU. para mitigar el impacto del estallido de la burbuja puntocom generó un ciclo de alta liquidez internacional.

Como lo señalan Kern y Nemiña (2017), en el plano político se observó un doble desplazamiento de poder: de Occidente a Oriente, y del Norte al Sur global. Los países y regiones más dinámicos en términos económicos buscaron aumentar su poder de decisión en el plano internacional. Así, China y Asia, el bloque Brics y los exportadores de materias primas aprovecharon su renovada fortaleza externa para acrecentar su capacidad de decisión en las instituciones y mecanismos centrales de la gobernanza económica internacional.

Luego de las crisis del neoliberalismo, en América Latina se instaló una ola de gobiernos progresistas críticos de los postulados del Consenso de Washington, que alentaron el crecimiento económico junto a una mejora en la distribución del ingreso y los servicios sociales. Se trataba de gobiernos que recuperaban el rol del Estado, reconocían las nuevas formas de organización política y planteaban una lógica de integración regional: posneoliberal y poshegemónica. De acuerdo con Rigirozzi y Tussie $(2012,2017)$, la poshegemonía destaca el margen político para construir agendas desde la periferia, como resultado del desplazamiento de la gobernanza neoliberal unipolar dominada por los EE. UU. vis a vis el ascenso de China. De este modo, menos que un engranaje en la correa de transmisión del poder, la región se abre espacio para la construcción política autónoma a través de estructuras regionales y prácticas híbridas.

Según las autoras nombradas, en tanto espacio para generar una integración alternativa, el regionalismo poshegemónico tuvo tres procesos paralelos que convergían en expresar vías de integración política y económica pensadas desde el Sur, pero divergían en las orientaciones y el grado de confrontación con el Norte. Prime- 
ro, los procesos de vinculación motorizados por una lógica en esencia comercial y orientada hacia los EE. UU., como la Alianza del Pacífico y el TLCAN: construcciones que procuraban forzar espacios para complementar la lógica comercial con el desarrollo económico y político: tal es el caso del Mercosur, la Unasur y la Celac. Y segundo, procesos que combinaban dimensiones políticas, económicas y culturales desde una perspectiva crítica con el statu quo, como la Alianza Bolivariana para los Pueblos de Nuestra América (ALBA).

En el caso argentino, si bien algunos de los pilares macroeconómicos -el tipo de cambio estable y competitivo y los superávits comercial y fiscal- habían sido establecidos durante la presidencia de Duhalde, desde 2003 la construcción política se orientó con base en los postulados del neodesarrollismo. Según Bresser Pereira (2007) y Gezmiş (2017), este alude a una nueva forma de orientación de la política pública que se aleja del neoliberalismo, sin que esto implique volver al viejo desarrollismo. El neodesarrollismo rechaza el dogma del libre mercado y la teoría del derrame como vías únicas para el crecimiento, y resalta que mercados competitivos requieren estados fuertes. Sin promover una economía estatista, resalta la importancia de la intervención del Estado en la economía, del crecimiento con eje en la actividad productiva y el pleno empleo, y de los controles en la cuenta de capital para moderar la volatilidad externa. Varesi (2011) agrega que, en Argentina, la implementación incluyó especialmente una política activa de ingresos y transferencias hacia los sectores subalternos.

Las transformaciones en el modelo de desarrollo, junto al rechazo al ALCA en 2005, promovieron un giro en la política exterior y, en particular, en la política financiera, que expresó el momentum poshegemónico'. En este sentido, la estrategia de inserción externa durante el kirchnerismo reflejó una serie de principios que dieron cuenta de este viraje. En primer lugar, se abandonó la inserción basada en el realismo periférico y se la reemplazó por otra de corte autonomista. A diferencia de la década de 1990, cuando Argentina abrazó de manera abierta la globalización neoliberal y su política exterior reforzó la dependencia, el autonomismo configuró una política exterior más activa y selectiva, que buscó promover los vínculos útiles para el modelo de desarrollo y alejarse de los que planteaban tensiones. Si, como lo señala Simonoff (2009), la integración al mundo occidental a través de la implementación de las reformas de mercado, liberalización y apertura promovidas por las potencias y las instituciones financieras internacionales con sede en Washington

Un reflejo de este momento poshegemónico, que analiza Clemente (2017), fue la aparición de diversos consensos, como el de Buenos Aires y China, que enfrentaban desde la periferia y el Sur global los postulados del Consenso de Washington como vía para el desarrollo. Otros, como el Consenso de los Commodities, destacan las consecuencias económicas y sociales negativas del neodesarrollismo (al respecto, véase Svampa, 2012). 
habían terminado en la crisis económica más profunda de la historia, era necesario plantear un giro drástico en la vinculación externa, de manera que se potenciaran los vínculos con aquellas naciones que planteaban una complementariedad positiva para el proceso de crecimiento económico y la resolución de la crisis de la deuda. Como lo señalan Actis et al. (2016), para Kirchner la vinculación con el mundo debía guiarse a partir de los intereses nacionales, centrados en el crecimiento económico con eje en la actividad productiva e inclusión social.

Así, Argentina reorientó su atención a la esfera regional como espacio privilegiado de vinculación externa. De acuerdo con Actis et al. (2016), esto implicó matizar la identidad "primermundista" y potenciar el perfil latinoamericanista, en especial a través de las relaciones con el bloque del Mercosur, que aparecía como una plataforma para potenciar a nivel regional el proceso de desarrollo, y, más adelante, con el resto del Cono Sur a través de la Unasur.

La reconfiguración de su identidad como país en desarrollo llevó a jerarquizar los vínculos y promover alianzas con los países del Sur global, con el objetivo de lograr mayor autonomía ante las instituciones financieras internacionales y promover un orden económico multilateral más favorable a los países en desarrollo². Esto cobraba especial importancia toda vez que, en 2003, aún restaba enfrentar la renovación del vínculo con el FMI y encarar la restructuración de la deuda, entre otros desafíos. En este sentido, por efecto de la devaluación y la emisión de títulos para compensar a los ahorristas, deudores y bancos, la deuda pública ascendía a fines de 2003 a 178.000 millones de dólares, lo cual equivalía a casi una vez y media el producto anual según Damill, Frenkel y Rapetti (2005, p. 217).

En el caso argentino, según Castiglioni (2013) y Trucco (2012), el enfoque poshegemónico en la dimensión financiera alentaba la toma de distancia de los mercados internacionales de capital y las instituciones financieras de Bretton Woods, aprovechando el margen de decisión abierto por el default, y exploraba vías de financiamiento alternativas que privilegiaran mecanismos regionales y articulaciones entre países en desarrollo que conllevaran menor condicionalidad, préstamos de organismos multilaterales con los que había mayor afinidad política y la utilización de los recursos del Banco Central. Asimismo, implicaba promover acuerdos monetarios y nuevos mecanismos de financiamiento regionales para desplazar al dólar y poner a disposición recursos para apuntalar la inversión pública, respectivamente. En este sentido, el conflicto con los acreedores externos sobre la reestructuración

2 Esto no implica perder de vista las diferencias estructurales al interior del Sur global. Al respecto, Fernández, Lauxmann y Trevignani (2014, p. 638) señalan que el desarrollo acelerado del este de Asia, basado en la industrialización vis a vis la reprimarización de América Latina, podría llevar a la aparición de nuevas formas de subordinación dentro del mismo bloque. 
de deuda, que marcó todo el periodo kirchnerista, pivotó sobre la tensión con el sector financiero internacional y los organismos multilaterales, derivada esta última del desplazamiento de la lógica de mercado como principio ordenador de la estrategia financiera externa.

\section{EL CANJE DE DEUDA Y EL PAGO AL FMI}

Al asumir la presidencia en 2003, Kirchner encontró una economía en proceso de recuperación, motorizada por el consumo privado, la inversión y las exportaciones. Asimismo, comenzaban a consolidarse los tres ejes sobre los que, según el Cenda (2010), se apoyaría el régimen de la posconvertibilidad: tipo de cambio competitivo para alentar la actividad productiva (de representar el 31,5\% del PIB en promedio entre 1993 y 2001, la producción de bienes significó el 40 \% del PIB en promedio entre 2002 y 20103); superávit comercial, el cual disminuía la vulnerabilidad externa; y superávit fiscal, efecto del aumento de los ingresos y la disminución del gasto real y del servicio de la deuda, que otorgaba margen para controlar el tipo de cambio y evitaba recurrir al endeudamiento como fuente de financiamiento (Cenda, 2010).

En relación con el frente externo, el gobierno tenía por delante las complejas negociaciones por la renovación del acuerdo Stand-by con el FMI y la renegociación de la deuda con los acreedores privados. Mientras que el Fondo se mostraba inflexible con el fin de evitar asumir su corresponsabilidad en la crisis de su otrora "mejor alumno", tal como lo analizaron Bembi y Nemiña (2007), la deuda argentina alcanzada por la cesación de pagos - por entonces la más grande del mundo- incluía ciento cincuenta y dos instrumentos, nominados en siete monedas y bajo jurisdicción de ocho legislaciones, según Alonso (2016). Kirchner desplegó una estrategia de negociación confrontativa con el sector financiero y los organismos multilaterales que, según Busso (2014), expresaba la crítica a los actores que habían promovido las reformas estructurales de la década de 1990 y eran señalados como corresponsables de la crisis económica de 2001; y, de acuerdo con Burín (2005), se sostenía en el apoyo casi unánime de los sectores económicos dominantes locales y la afinidad con la política financiera de reducción del riesgo moral que promovía la gestión republicana de Bush en los EE. UU.

Luego de una negociación tensa, que incluyó una breve cesación de pagos de Argentina con el Fondo, Kirchner renovó el acuerdo con el FMI por tres años, evitando aceptar las condiciones más exigentes ${ }^{4}$. Mientras que el Fondo reclamaba un superávit primario del $5 \%$ del PIB y condicionar su uso para garantizar una oferta

3 Datos del Mecon.

4 Para una revisión en detalle de las negociaciones por este acuerdo, véase Nemiña (2011). 
beneficiosa a los acreedores, el gobierno logró imponer un techo del 3 \% y plantear una propuesta de reestructuración que no estableciera una carga tan gravosa sobre el presupuesto y el crecimiento. El acuerdo con el Fondo permitía compensar los vencimientos con el organismo a través de nuevos créditos, lo cual era condición necesaria para encarar con mayor margen de negociación la reestructuración de deuda.

En su primera oferta, sobre un stock de deuda impaga de 87.000 millones de dólares el Gobierno propuso una quita del 75 \% sobre el valor nominal según Damill, Frenkel y Rapetti (2005, p. 219). Si bien contaba con la simpatía de EE. UU., que buscaba mostrar al mundo financiero un ejemplo aleccionador para limitar los comportamientos especulativos, debido a la oposición de los acreedores, de gran parte del G7 y del FMI, el gobierno planteó una segunda oferta con una quita levemente menor, más la inclusión de un cupón que devengaría intereses cuando la economía creciera por encima del 3 \% anual; de todas formas, y según Val (2017), fue una propuesta que los acreedores consideraron agresiva.

Poco después, el Fondo condicionó la revisión del acuerdo a que el Gobierno mejorara una vez más los términos de la oferta, aumentara el ahorro fiscal y las tarifas de los servicios públicos, y bajara el tipo de cambio para facilitar la adquisición de dólares y aumentar la capacidad de repago de la deuda. Pero apoyado por gran parte del arco político y las principales agrupaciones de empresarios y trabajadores, y por una posición externa más holgada, el gobierno suspendió el acuerdo. Desde entonces, Argentina dejó de recibir desembolsos del FMI y debió afrontar los vencimientos de capital con sus propios recursos, aunque a cambio evitó introducir nuevas mejoras a la oferta a los acreedores y modificar la orientación del programa económico.

En marzo de 2005 concluyó el primer canje de deuda, que se realizó sin la mediación del FMI. El 76,15 \% del total de la deuda en default ingresó al canje, lo cual permitió disminuir el stock de deuda pública en unos 67.000 millones de dólares (cayó del 139 \% al 73 \% del PIB) y reducir la exposición al riesgo cambiario, ya que un $44 \%$ de los nuevos títulos fue emitido en moneda nacional con una indexación al índice de precios (Damill, Frenkel y Rapetti, 2005, p. 225).

En el marco de los avances logrados en relación con la resolución de la cesación de pagos, la decisión de no emitir nueva deuda en los mercados internacionales de capital y la continua cancelación neta de vencimientos con el Fondo, el gobierno postuló hacia finales de 2004 la llamada estrategia de desendeudamiento, cuyo objetivo fue reducir la dependencia financiera externa y ganar grados de libertad para hacer política económica. Poco después, y con pocos días de diferencia, Brasil y 
Argentina cancelaron por anticipado la deuda que mantenían con el FMI - 15.500 y 9.800 millones de dólares, respectivamente-. La medida fue vista como un avance hacia una mayor coordinación económica sudamericana, en línea con el rechazo al ALCA en la Cumbre de las Américas de ese año en Mar del Plata. El distanciamiento con el Fondo se profundizó en los años siguientes, cuando Argentina dejó de realizar las revisiones anuales del organismo (llamadas "del Artículo IV" de manera coloquial). Para realizar el pago, el Gobierno tomó prestadas las reservas del Banco Central a cambio de una letra intransferible en dólares a diez años, recurso que utilizaría de manera decidida un lustro más tarde para cancelar deudas con privados. Según Bembi y Nemiña (2007), esto permitió al Gobierno sostener el crecimiento basado en la promoción del mercado interno, con su correlato en el aumento del empleo y la producción, y evitar reabrir la negociación con los acreedores que no habían entrado al canje, tal como lo reclamaba el Fondo.

Los años siguientes estuvieron marcados por un pujante crecimiento económico con distribución del ingreso y una aceleración de la inflación. Debido a que los títulos en moneda nacional posdefault incluyeron una cláusula de indexación por la inflación (el coeficiente de estabilización de referencia o CER) para incentivar su aceptación, según Bordón (2017), entre 2006 y 2008 el stock de deuda se incrementó en más de 12.000 millones de dólares. Frente a esta situación, a comienzos de 2007 el gobierno modificó el cálculo de la inflación y subestimó de forma sistemática la variación del índice de precios, lo que le permitió generar un ahorro significativo en las rentas devengadas por el CER ${ }^{5}$. El sector financiero respondió a este aumento de la incertidumbre con una suba de la tasa de interés, lo cual reforzó los incentivos del gobierno a financiarse con las reservas, habida cuenta del spread que había entre la tasa de interés que cobraban los bancos y que percibía el Banco Central de la República Argentina (BCRA) por sus depósitos en divisas en el exterior.

\section{EL DEBATE SOBRE EL DESENDEUDAMIENTO}

Si bien surgió como el resultado colateral de la abstención a emitir deuda en los mercados internacionales ante el riesgo de sufrir un embargo por parte de los holdouts y la suspensión del acuerdo con el FMI, el desendeudamiento fue el eje rector que orientó la política externa en función del interés por reducir la dependencia financiera hasta mediados de 2013, cuando el agudizamiento de la restricción externa y el impacto del fallo de Griesa motivaron un giro hacia el endeudamiento (ver más adelante).

\footnotetext{
5 El Estudio Bein calculó en 22.500 millones de dólares el ahorro solo entre 2007 y 2009 (Ámbito Financiero, 2010).
} 
Como lo apunta Bordón (2017), el desendeudamiento no se definía por la reducción absoluta sino relativa del endeudamiento, esto es, la disminución del stock de deuda pública, de deuda externa y de la proporción de los intereses y el servicio de la deuda sobre el producto bruto. La política de desendeudamiento encontraba su fundamento menos en un rechazo dogmático al endeudamiento, que en establecer un horizonte sostenible para la deuda con el fin de evitar endeudarse con actores cuyas lógicas y condiciones pusieran en tensión las bases del modelo de acumulación.

La trayectoria de la deuda pública nominal durante la posconvertibilidad muestra que, luego de llegarse al mínimo de 125.000 millones de dólares en 2005, como resultado de los canjes y refinanciaciones, la deuda inició un sendero ascendente en términos nominales. Sin embargo, la evolución del stock de deuda sobre el PIB ${ }^{6}$ muestra una trayectoria descendente que va desde el $141 \%$ en 2002 al $32 \%$ en 2013, año en el cual se revirtió el proceso frente a la restricción externa (gráfico 1).

Gráfico 1. Deuda pública de Argentina excluyéndose la deuda en cesación de pagos. Total y proporción sobre PIB, 1997-2017 (en millones de dólares corrientes)*

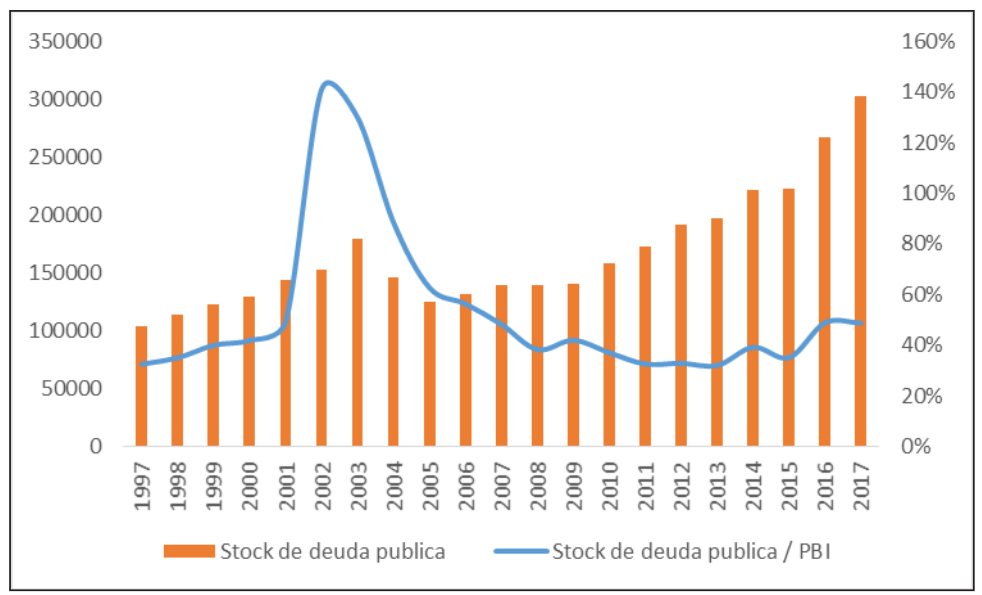

* Para todos los gráficos, el PIB se toma en dólares a precios corrientes base 2004, según datos del FMI.

Fuente: elaboración propia con datos del Ministerio de Finanzas (varios años) e IMF (2017).

La evolución de la deuda pública y los intereses sobre el producto muestran un sendero semejante. Como lo anotan Kulfas y Schorr (2003), el peso creciente de los intereses sobre el producto durante los años de la convertibilidad demuestra el carácter deuda dependiente del régimen convertible. El salto en el stock de deuda resultante del efecto de la devaluación junto a la recesión no es acompañado

6 Para todos los cálculos se toma el PIB en dólares a precios corrientes base 2004, según datos del FMI. 
por una trayectoria similar de los intereses, debido a que la cesación de pagos libera de manera transitoria al presupuesto de esa carga; los pagos de intereses de deuda sobre el PIB entre 2005 y 2015 tuvieron una trayectoria estable con un promedio de 1,62 \% anual, visiblemente diferente al "círculo vicioso" de la convertibilidad. Vale destacar la instauración de una tendencia ascendente desde la asunción del nuevo gobierno, ya que los intereses sobre el PIB pasaron de 1,36 \% en 2015 a 1,95\% en 2017 (gráfico 2).

Gráfico 2. Deuda pública de Argentina excluyendo deuda en cesación de pagos. Stock e intereses sobre PIB, 1997-2017. En millones de dólares corrientes

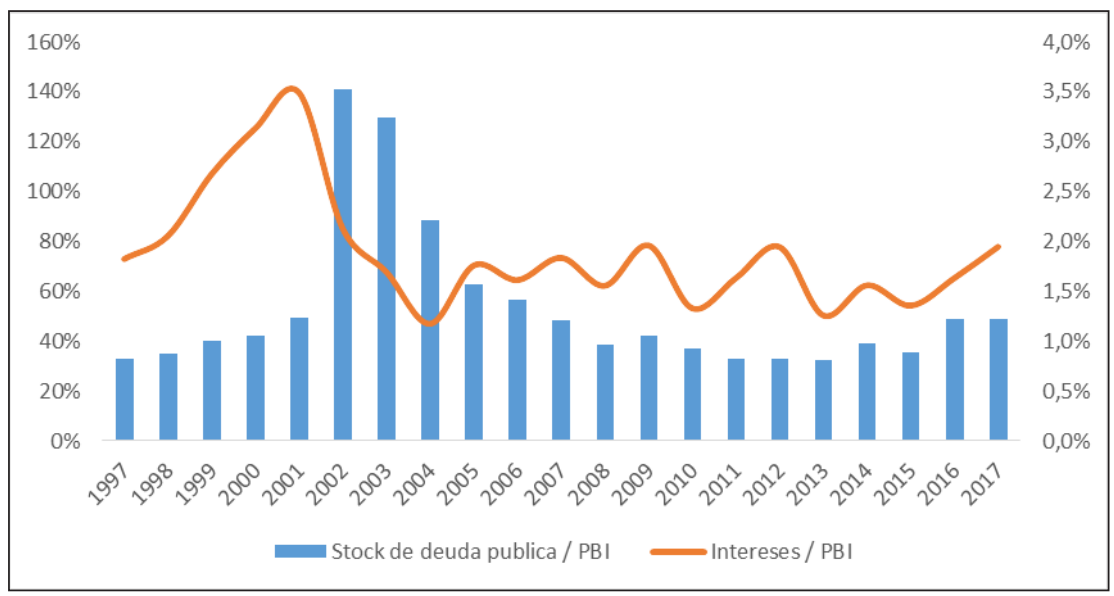

Fuente: elaboración propia con datos de los ministerios de Finanzas (varios años) y Hacienda (2018).

Por otra parte, la proporción de deuda externa sobre el total de deuda pública mostró un descenso persistente durante todo el periodo: de 73,6 \% a 28,8 \% en junio de $2015^{7}$ (gráfico 3). El robusto superávit de cuenta corriente, junto a la decisión de evitar las condicionalidades ortodoxas que imponen los organismos multilaterales tradicionales, llevó a reducir el financiamiento de estas instituciones, del cual el pago anticipado al FMI es un ejemplo paradigmático. No obstante, cuando hacia 2010 la cuenta corriente se volvió deficitaria, el gobierno apeló a los recursos del BCRA en lugar de recurrir a los mercados internacionales de capital para morigerar los grados de dependencia financiera externa.

Por último, el peso de los intereses y el servicio de la deuda sobre los recursos tributarios también mostró un descenso marcado frente a los valores de la convertibilidad, y una estabilización en el 8,9 \% y 37,5 \% en promedio para el periodo 2005-2015 (gráfico 4).

$7 \quad$ Último dato disponible. 
Gráfico 3. Deuda pública de Argentina. Detalle de deudas interna y externa y proporción de esta última sobre el total, 1997-2015 (en millones de dólares corrientes)

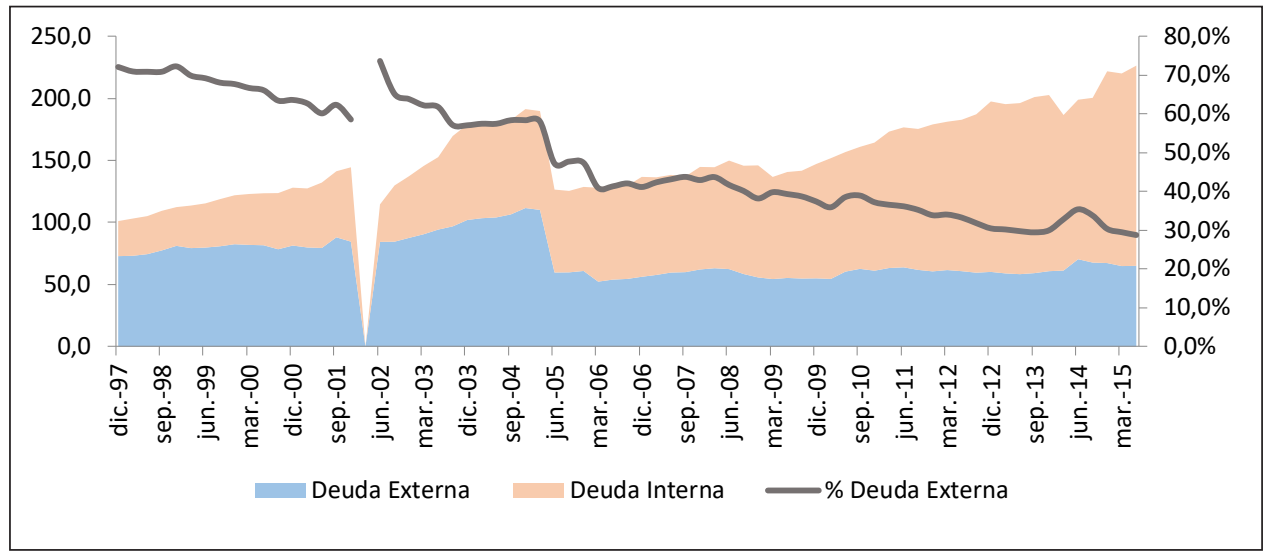

Fuente: elaboración propia con datos del Ministerio de Finanzas (varios años).

Gráfico 4. Deuda pública de Argentina. Intereses y servicio de la deuda sobre recursos tributarios, 2000-2015 (en millones de dólares corrientes)

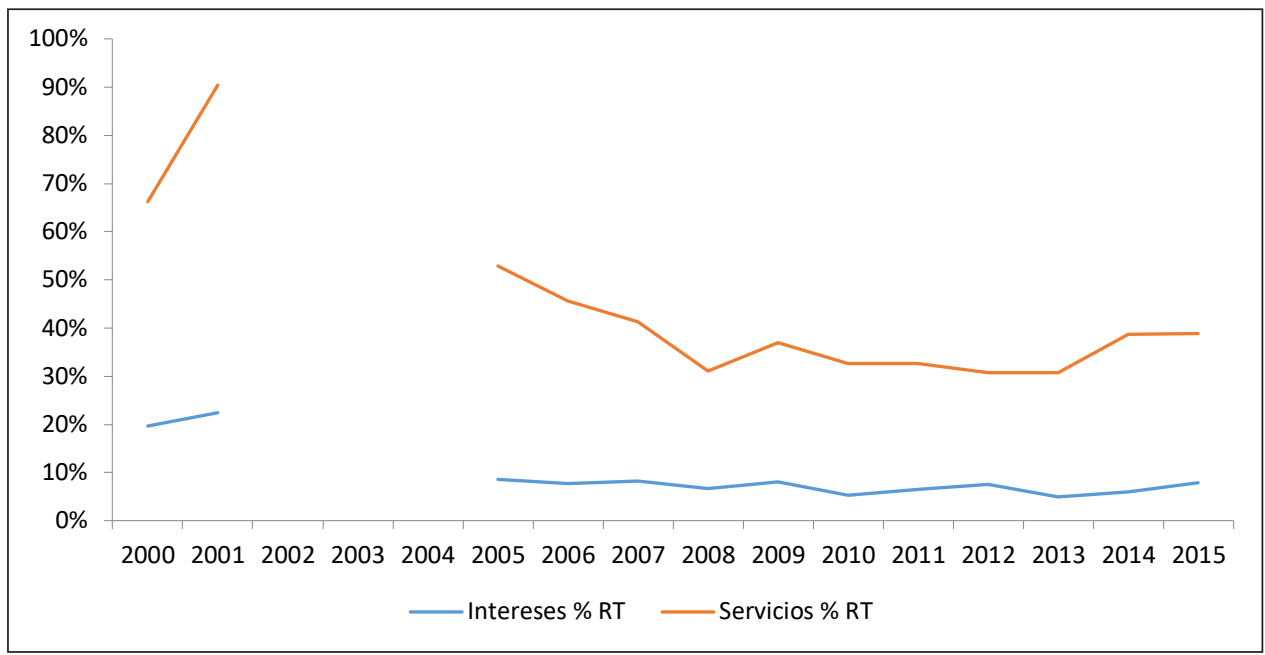

Fuente: elaboración propia con datos del Ministerio de Finanzas (varios años).

Si bien autores como Cenda (2010), Kulfas (2016) y Peralta Ramos (2007) destacan que el desendeudamiento permitió reducir la dependencia financiera externa y ganar grados de libertad para hacer política económica, otros han planteado críticas que pueden ordenarse en tres grupos ${ }^{8}$. Primero, autores como Lo Vuolo y

8 Para un análisis detallado, véase Bordón (2017). 
Seppi (2008) criticaron el impacto financiero del diseño de los nuevos instrumentos otorgados a partir del canje de deuda: según ellos, la indexación al índice de precios al consumidor de los títulos en moneda local y las unidades vinculadas al PIB implicaron un incremento del stock de deuda que no estaba contabilizado, dado su carácter flotante 9 . Por otra parte, si bien otorgó oxígeno financiero al reducir el servicio de la deuda durante los primeros años, algunas imperfecciones en el diseño de la unidad vinculada al PIB generaron que la postura agresiva de Argentina no generara un beneficio financiero acorde a los costos políticos que asumió. Argentina propuso una quita del $73 \%$ sobre el valor presente a 2005, sustantivamente mayor a la quita promedio de $42 \%$ para todas las reestructuraciones de países de ingreso medio posteriores al plan Brady; eso contribuye a comprender que la tasa de aceptación de poco más del 75 \% fuera la segunda más baja entre las 17 reestructuraciones de deuda soberana desde 1998, según datos de Cruces y Levy Yeyati (2016). No obstante, los bonos posdefault incorporaron un cupón que reportaba una renta adicional en relación con el crecimiento; debido a que se subestimó la tasa de crecimiento futura para el cálculo de los pagos, este instrumento proporcionó una renta extraordinaria e inesperada para sus tenedores, ya que, según Campos (2008), no fue valorado al momento del canje debido a su carácter no convencional y baja liquidez. Por tal motivo, Müller (2013, p. 30) señala que la renta generada por el cupón del PIB redujo la quita efectiva a un valor comprendido entre 21 \% y 36 \% en relación con el valor técnico de los títulos entregados en los canjes, según la tasa de descuento que se tome.

En segundo lugar, Giuliano (2015) criticó que el reemplazo de deuda externa por interna reflejaba una escasa vocación de pago. Uno de los casos emblemáticos en este sentido fue el pago adelantado al FMI utilizando las reservas del BCRA, mecanismo que sería utilizado a partir de 2010 para cancelar deudas con privados. Como fue señalado, el desendeudamiento no buscaba la reducción nominal de la deuda -por cierto, un criterio que ningún país ni organismo internacional propone-, sino la disminución de la dependencia financiera externa. En este sentido, el cambio de acreedor permitía ganar grados de libertad financiera toda vez que se evitaban las condicionalidades implícitas o explícitas que el FMI, los acreedores privados internacionales y otros actores financieros como las calificadoras de riesgo imponen a los deudores, tal como lo señala Chesnais (2001). Así, la apelación a recursos propios permitió al gobierno sostener el crecimiento basado en la promoción del mercado interno, con su correlato en el aumento del empleo y la producción.

También se criticó la emisión fechada el 31 de diciembre de 2003, lo cual implicó otorgar bonos que incluían más de un año de intereses devengados (Bordón, 2017). 
Cantamutto y Ozarow (2016) y Lo Vuolo y Seppi (2008), entre otros, criticaron que el canje de deuda y el pago adelantado al FMI enmarcados en la política de desendeudamiento implicaron reconocer deuda pasible de ser catalogada como ilegítima. Respecto del pago al FMI, y según Bohoslavsky (s. f., p. 9), este no implicó necesariamente renunciar a futuros reclamos por la corresponsabilidad del organismo en la crisis, toda vez que se realizó de una forma semejante al pago bajo protesto, como se deriva de la argumentación oficial cargada de reproches contra las políticas de ajuste que el FMI promovió en Argentina. Por otra parte, el pago adelantado al FMI afectó las finanzas del Fondo al profundizar su déficit operativo, ya que su principal ingreso deriva del interés que cobra sobre sus créditos. Esto implicó erosionar su capacidad de injerencia sobre la política económica de los países deudores, lo cual, según Nemiña y Larralde (2018), profundizó su deslegitimación y potenció el reclamo de los países en desarrollo por una redistribución de los votos dentro del organismo, a fin de adecuarla a la nueva estructura de poder en la economía internacional.

Con relación al canje de deuda, una auditoría como la postulada requiere fundamentos jurídicos y amplio apoyo político interno. Si el fallo del juez Ballesteros otorga elementos suficientes en términos jurídicos, no es claro -desafortunadamente- que ese planteamiento fuera la expresión de un reclamo social mayoritario, lo cual siembra interrogantes sobre la sostenibilidad política de tal iniciativa. Asimismo, una auditoría no garantiza mejores resultados financieros. A título comparativo, la restructuración de dos títulos Brady que Ecuador realizó en 2009 luego de la auditoría de la deuda derivó en una quita a valor presente del 67,7 \%, contra el 76,8 \% que tuvo la restructuración argentina según Cruces y Trebesch (2013, p. 30); eso no evitó al país andino acordar la recompra de los títulos pendientes en cesación de pagos en 2014 para volver a los mercados internacionales de capital (Feibelman, 2017, p. 57).

\section{VIVIR CON LO NUESTRO -Y UNA "AYUDITA" EXTERNA-: EL IMPACTO DE LA CRISIS FINANCIERA GLOBAL}

Hacia mediados de 2008, la economía había disminuido el ritmo de crecimiento a causa del conflicto entre el gobierno y el sector agropecuario por la instauración fallida- de retenciones móviles a las exportaciones de oleaginosas. Poco después se produjo la quiebra del banco de inversión Lehman Brothers, que disparó el estallido de la crisis financiera internacional más profunda desde la de 1930.

La crisis no afectó a Argentina por el canal financiero, debido a la baja dependencia de los mercados internacionales de capital y la robusta posición externa en términos de reservas y bajo nivel de endeudamiento; en cambio, la caída del co- 
mercio internacional (los precios de los alimentos se desplomaron un 40 \%) llevó a una caída del $11 \%$ de las cantidades y los precios de las exportaciones argentinas, y generó una retracción del 6 \% del PIB en 2009, según datos de Porta, Santarcángelo y Schteingart (2017, p. 119).

Para enfrentar el impacto externo, el gobierno desplegó una política contracíclica en los planos comercial, fiscal y financiero. Con el fin de mantener el superávit comercial, se limitaron de manera informal las importaciones para compensar la caída de las exportaciones entre 2008-2009. Por otra parte, se implementó un fuerte impulso fiscal a través de un aumento del gasto real primario traccionado por la obra pública, el empleo y las remuneraciones reales públicas. En el plano financiero, la nacionalización de las administradoras de fondos de jubilaciones y pensión (AFJP) en 2008 implicó, según Cifra (2009, p. 26), el traspaso al Estado de unos 25.000 millones de dólares en activos que eran administrados por las AFJP, más la apropiación de un flujo anual de unos 4.000 millones de dólares (entre aportes de los trabajadores y contribuciones patronales) que incrementaron los recursos fiscales. Esto permitió potenciar las políticas contracíclicas y reducir la dependencia financiera. Con respecto al último punto, más del 50 \% de los activos recibidos eran títulos de deuda nacional.

El aumento de la tasa de interés internacional reforzó la búsqueda de mecanismos de financiamiento alternativos a los mercados privados para apuntalar las reservas. Para eso, el gobierno apeló al BCRA como vehículo principal de financiamiento: gestionó créditos de corto plazo del Banco de Pagos Internacionales y el Banco de Francia, que llevaron el stock de préstamos externos con organismos oficiales a 5.800 millones de dólares a comienzos de 2009 (gráfico 5); suscribió un swap preventivo de monedas con el Banco Central Chino de 3 años de duración por el equivalente de 10.200 millones de dólares (que no fue utilizado); y, a partir de 2010, utilizó las reservas de libre disponibilidad ${ }^{10}$ para cancelar compromisos con acreedores privados. Asimismo, como resultado del consenso entre los países del G20 de implementar políticas monetarias expansivas para enfrentar la crisis, el FMI aprobó una asignación extraordinaria de Derechos Especiales de Giro, merced a la cual Argentina recibió 2.600 millones de dólares, equivalentes por entonces el $5,87 \%$ de las reservas. La importancia del BCRA como vehículo de obtención de financiamiento externo se refleja en el aumento de su deuda externa nominal, que entre el tercer trimestre de 2007 y 2009 se incrementó en un 133 \%; además, durante el mismo periodo, la proporción de deuda externa del BCRA sobre el total de deuda externa sufrió un incremento semejante: pasó del 2,12 \% al 4,8 \% (gráfico 5).

10 Se trata de las reservas que exceden el $100 \%$ de la base monetaria. 
Gráfico 5. Deuda externa del BCRA. Detalle por tipo de acreedor y proporción sobre el total de la deuda externa pública, 2006-2015 (en millones de dólares corrientes)

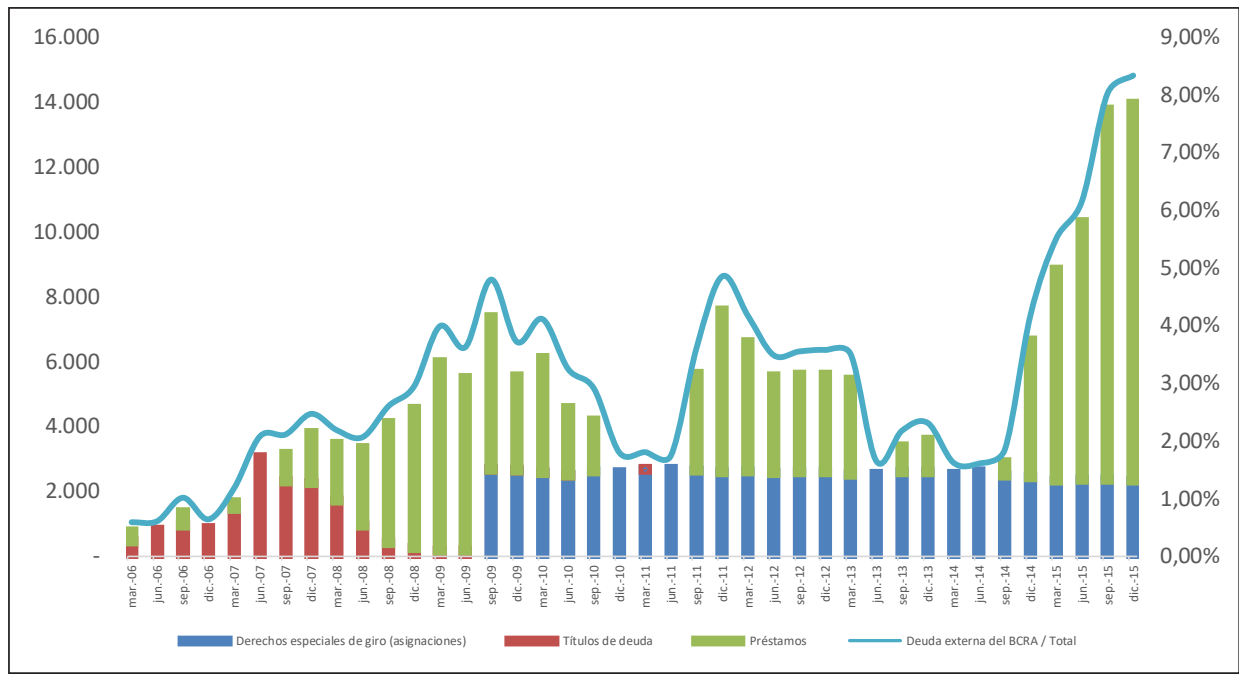

Fuente: elaboración propia con datos del Indec (2018).

La búsqueda de mayores grados de autonomía financiera no se limitó a iniciativas de alcance nacional. En línea con los principios del regionalismo poshegemónico, el gobierno promovió con ímpetu -aunque con éxito dispar- diversas vías de financiamiento y la creación de mecanismos alternativos que proporcionaran recursos ante dificultades en la balanza de pagos sin condicionalidades ortodoxas. En primer lugar, entre 2005 y 2008, Venezuela realizó sucesivas suscripciones directas de títulos por al menos 5.600 millones de dólares (Infobae, 5 de octubre de 2013) que, si bien incrementaron el endeudamiento, evitaron recurrir a los volátiles mercados privados internacionales. Por otra parte, en el marco de la Unasur se potenció a la CAF como el Banco de Desarrollo de América Latina mediante un aumento de sus recursos, que permitió más que duplicar su cartera de créditos de 10.184 a 21.818 millones de dólares entre 2008 y 2016. Entre los integrantes del ALBA y el Cono Sur se promovieron diversas iniciativas para desplazar al dólar como moneda de intercambio entre los países de la región; de ellas cabe mencionar el Sucre y el Sistema de Pagos en Moneda Local entre Brasil y Argentina, si bien sus avances son limitados. Por último, el Mercosur y los miembros sudamericanos del ALBA crearon el Banco del Sur con el fin de potenciar el financiamiento multilateral para infraestructura y desarrollo; pero, según Ortiz y Ugarteche (2009), diferencias respecto del esquema de gobernabilidad, la estructura organizativa y de funcionamiento detuvieron su avance.

De acuerdo con Abeles y Kiper (2010), el breve pero trascendental "consenso keynesiano" logrado en las cumbres del G20 posteriores a la crisis impulsó el creci- 
miento internacional, lo cual contribuyó a que la economía local mostrara tasas de crecimiento del 10,4 \% y 6,2 \% para 2010 y 2011, respectivamente (según datos de Porta et al., 2017). En 2010 el gobierno lanzó el segundo canje de deuda que permitió sustituir unos 17.500 millones de dólares en títulos que permanecían en default en las mismas condiciones que el primer canje; esto redujo al 7 \% la deuda privada pendiente de reestructuración (es decir, sin contar los atrasos con el Club de París), equivalente a unos 11.000 millones de dólares nominales, incluidos los intereses devengados. Una parte significativa de los holdouts eran fondos buitres que no estaban dispuestos a entrar al canje y habían iniciado juicios en EE. UU. para cobrar el total de sus acreencias.

\section{REGRESO FALLIDO A LOS MERCADOS Y LA VÍA CHINA}

En 2011, la economía enfrentaba una serie de desequilibrios macroeconómicos. Entre los más importantes, Porta et al. (2017) mencionan la apreciación cambiaria, un nivel de inflación que no bajaba del $25 \%$, el deterioro de la balanza comercial, el aumento de las importaciones de energía y un incipiente déficit fiscal. El déficit de cuenta corriente (gráfico 6) y la caída de la actividad en Brasil aumentaron las expectativas de devaluación, lo cual disparó la fuga de capitales en ese año al récord histórico de 25.628 millones de dólares, equivalentes al 2,95 \% del PIB medido a PPP (Gaggero, Gaggero y Rúa, 2015).

Gráfico 6. Balanza de pagos de Argentina: resumen 1998-2015 (en millones de dólares corrientes)

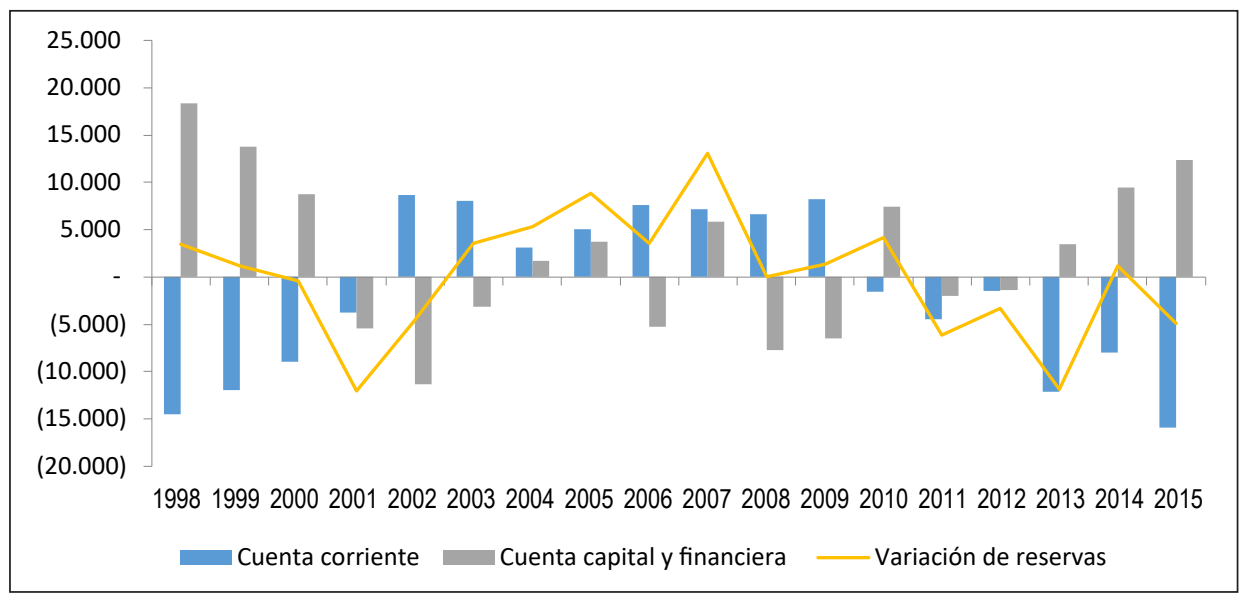

Fuente: elaboración propia con datos del Indec (2018).

Aunque se reconocía la necesidad de introducir cambios en la política económica para evitar que el proceso de crecimiento y distribución del ingreso se viera 
afectado, existían diferencias dentro del equipo económico. Porta et al. (2017, p. 125) señalan que el ministro de economía (luego vicepresidente) Boudou era partidario de un regreso a los mercados financieros y una normalización de las relaciones con el FMI; mientras que otros miembros del equipo, como Kicillof y Moreno, anteponían mantener el desendeudamiento. Luego del triunfo categórico de Cristina Fernández de Kirchner en la elección presidencial de ese año se optó por mantener el tipo de cambio como ancla nominal, se implementaron controles de cambio para limitar la caída de las reservas y se apeló de nuevo a los créditos oficiales de corto plazo al BCRA (gráfico 5).

Un año más tarde, en 2012, el gobierno promovió otras medidas relevantes. Primero, se reformó la Carta Orgánica del BCRA y se facultó a la autoridad monetaria a promover la estabilidad monetaria y el pleno empleo. Para ello, se le permitió aumentar su financiamiento al Tesoro, lo cual permitió al gobierno financiar el déficit fiscal con emisión monetaria (gráfico 7).

Gráfico 7. Argentina: deuda pública; proporción por tipo de acreedor (excluye títulos y atrasos) sobre el total, 2001-2015 (en millones de dólares corrientes)

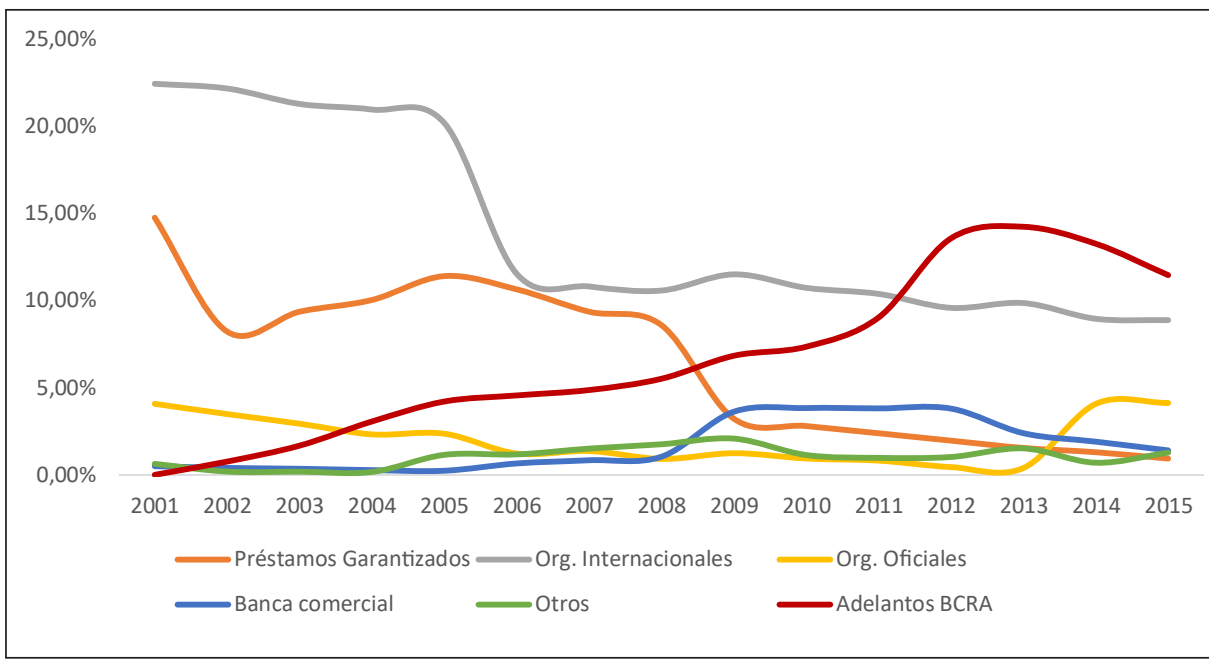

Fuente: elaboración propia con datos del Ministerio de Finanzas (varios años).

En segundo lugar, aunque las reservas se habían estabilizado, los controles cambiarios se profundizaron y el gobierno planteó -con más voluntarismo que eficacia- una política de desdolarización; además, se reforzaron los obstáculos a las importaciones mediante declaraciones juradas anticipadas. No obstante, esto aumentó la incertidumbre sobre la estabilidad del tipo de cambio, lo cual aumentó la demanda de dólares en el mercado paralelo y la brecha con el precio oficial. 
Ante un escenario económico y político adverso, que redundó en una derrota en las elecciones legislativas, el gobierno promovió un cambio en el equipo económico, a partir del cual se produjo un giro en la política económica -y en especial, financiera- favorable a flexibilizar algunos de los controles vigentes. A los ingresos de Kicillof y Fábrega al ministerio de Economía y la presidencia del BCRA, respectivamente, siguió una flexibilización de los controles cambiarios y una devaluación del $20 \%$ para dar competitividad al tipo de cambio. Aunque se incrementó la tasa de interés, la depreciación aceleró el aumento de precios, con lo cual se borró la ganancia de competitividad buscada.

En el plano financiero, una aceleración del endeudamiento y un moderado aumento de la deuda en relación con el producto mostraban un giro en la estrategia financiera (véase el gráfico 1). En este marco, el gobierno insinuó un acercamiento a los mercados privados de capital, para lo cual resolvió de manera expeditiva tres conflictos externos que obstaculizaban ese camino. Días antes de las elecciones legislativas resolvió un largo conflicto en el Centro Internacional de Arreglo de Diferencias relativas a Inversiones (Ciadi) con cinco compañías extranjeras que reclamaban compensaciones por 677 millones de dólares. El gobierno canceló los pagos en bonos con una quita del $25 \%$ sobre el monto, y el compromiso de las empresas de incrementar sus inversiones en el país. A posterioridad, otorgó 5.000 millones de dólares en títulos a Repsol como indemnización por la expropiación del 51 \% de la petrolera YPF, ocurrida dos años antes. Por último, acordó el pago de la totalidad de la deuda sin ninguna quita con el Club de París, a cambio de promesas de inversiones por parte de las potencias centrales y evitar suscribir un acuerdo con el FMI. La negociación con el Club de París puso de manifiesto que, frente al aumento de las necesidades externas derivadas de la reaparición de la restricción externa, el gobierno priorizaba reanudar el financiamiento privado internacional antes que solicitar financiamiento del FMI, con el cual el vínculo estuvo marcado por el conflicto durante toda la gestión kirchnerista.

Sin embargo, la decisión inesperada de la Corte Suprema de los EE. UU. de dejar en firme el fallo de Griesa, que reconocía la totalidad del reclamo de los holdouts que habían iniciado demandas (incluidos intereses y punitorios en efectivo), obligó a revisar la estrategia financiera. De acuerdo con Guzmán (2016), debido a que los bonos del canje incluían una cláusula que les hacía extensible cualquier arreglo posterior que se ofreciera (RUFO, por sus iniciales en inglés), si el gobierno cumplía el fallo se exponía a que los acreedores que habían aceptado el canje reclamaran compensaciones que podían llegar a los 200.000 millones de dólares; no cumplirlo ponía al país en desacato frente la Justicia norteamericana y se exponía a sanciones. En paralelo, Griesa bloqueaba los pagos a los acreedores que ha- 
bían aceptado el canje para forzar el cumplimiento de la sentencia favorable a los fondos buitres.

La situación obturó la posibilidad de obtener financiamiento en los mercados privados de capital, ya que Griesa había amenazado a imponer sanciones a cualquier institución financiera que ayudara al país mientras no cumpliera el fallo. Ante esta situación, el gobierno avanzó en dos sentidos. Primero, en el marco de la Asamblea General de la ONU promovió, junto al G77 y China, la sanción de un Marco de Reestructuración de Deudas Soberanas que, según Manzo (2017), busca limitar el accionar de los fondos buitres y repartir las cargas entre deudores y acreedores de manera más equitativa; y segundo, profundizó la relación económica con China, consolidado como su segundo socio comercial después de Brasil. Según Vadell et al. (2016), mediante la suscripción de diversos acuerdos de asociación estratégica se acordó una serie de inversiones chinas en proyectos de infraestructura y generación de energía, y se reactivó el swap por el equivalente a 11.000 millones de dólares. Si las inversiones expresaban una motivación productiva y financiera, el swap fue decisivo para evitar una crisis de balanza de pagos.

Lo anterior lleva a un marcado aumento de los préstamos externos al BCRA, que en su mayoría correspondían al swap, los cuales entre el segundo trimestre de 2014 y el final de 2015 pasaron de cero a 11.620 millones de dólares. Como consecuencia, se observa un notable aumento de la proporción de deuda externa del BCRA sobre el total de deuda externa, que en el mismo periodo pasó de 1,61 \% a 8,34 \% (véase el gráfico 5).

Si la profundización de la restricción externa agotó la posibilidad de recurrir a las reservas y alentó un moderado incremento del endeudamiento durante los dos últimos años del kirchnerismo, el fallo de Griesa profundizó, de forma paradójica, la estrategia financiera poshegemónica del gobierno en términos de la búsqueda de vías alternativas de financiamiento. Al obstaculizar el acceso a los mercados internacionales de capital, desplazó la demanda de financiamiento hacia la segunda potencia económica que le disputa de manera progresiva el liderazgo global a los EE. UU.

La apelación a China como vía complementaria de financiamiento alternativo no estaba exenta de costos. Como señala Oviedo (2015), mientras se profundizaba el vínculo con un país con el cual Argentina posee un comercio muy primarizado y deficitario, muchos de los proyectos de infraestructura acordados contemplaban elevadas transferencias de tecnología desde el país asiático que podían desplazar el desarrollo y la producción locales. No obstante, y a pesar de enfrentar restricciones, el financiamiento sin condicionalidades formales en el marco de una asocia- 
ción económica complementaria (aunque, por cierto, desigual) permitía al gobierno mantener los lineamientos centrales del programa económico y evitar plegarse a las recomendaciones del sector financiero internacional y los organismos multilaterales con sede en Washington, dos atributos centrales de una estrategia financiera poshegemónica que ponía la autonomía política en el centro.

\section{REFLEXIONES FINALES}

La reducción del peso del endeudamiento externo sobre la economía constituye uno de los principales legados del periodo kirchnerista. El stock de deuda pública a finales de 2015 era del $35 \%$ del PIB; mientras que el pago de intereses apenas superaba el $2 \%$ del PIB luego de alcanzar casi 4 puntos al final de la convertibilidad. Asimismo, buena parte de la deuda pública estaba en manos de otros organismos públicos, lo cual facilitaba su refinanciación.

Si bien la bonanza económica de los primeros años de la década de 2000 mejoró la posición externa de los países exportadores de materias primas, la gestión kirchnerista postuló el desendeudamiento desde los primeros años de su gestión como una política de Estado. El origen combinó convicción y necesidad. Por un lado, con el fracaso de la convertibilidad aún fresco, el gobierno promovió un modelo de acumulación que no estuviera expuesto a la volatilidad de los flujos financieros externos privados. Por otra parte, la cesación de pagos apartó al país del sector financiero global.

En este sentido, el desendeudamiento expresa la búsqueda por desplegar una inserción financiera poshegemónica, que permitiera evitar las clásicas condicionalidades ortodoxas que reclaman el sector financiero internacional y los organismos multilaterales con sede en Washington, y explorar mayores márgenes de autonomía. Esta estrategia incluyó: una dura renegociación de deuda con los acreedores privados que involucró una confrontación con el FMI; el pago de la deuda externa con recursos propios obtenidos vía superávit comercial, y luego a través del Banco Central; priorizar al financiamiento externo oficial por sobre el privado; y privilegiar el financiamiento multilateral a través de instituciones con las que había mayor nivel de afinidad política, como la CAF. En términos de economía política, la disminución relativa de la deuda externa erosionó el poder de los acreedores internacionales, las instituciones que promueven sus intereses como el FMI, y el sector financiero en general, dentro de los sectores dominantes de Argentina.

La política financiera externa de la Argentina durante el kirchnerismo atravesó tres fases. Entre 2003 y 2007 se estableció el desendeudamiento y, como resultado de un crecimiento acelerado, se realizaron la primera reestructuración de deuda 
privada y la cancelación anticipada de la deuda con el FMI, y se avanzó en la integración financiera regional. El segundo periodo, comprendido entre 2008 y 2013, se puede dividir en dos etapas: una primera, en la que el gobierno apela al financiamiento oficial externo para enfrentar la crisis financiera internacional y avanza en el segundo canje de deuda; y otra que comenzó en 2011, cuando, frente a la reaparición de la restricción externa y la aceleración de la fuga de capitales, se consolidó la estrategia de afrontar el pago de la deuda externa con reservas del Banco Central. Y en la tercera fase, ocurrida entre 2013 y 2015, se produjo un retroceso moderado en la estrategia de desendeudamiento; luego de un acercamiento fallido a los mercados internacionales de capital, se recurrió al financiamiento chino para evitar aceptar los condicionamientos que imponía el fallo de Griesa.

El triunfo de la coalición Cambiemos generó un giro drástico en la estrategia financiera externa del país en el sentido opuesto al observado durante la etapa anterior: de manera similar a lo que sucedió durante la década de 1990, el endeudamiento externo se consolidó como la principal fuente de entrada de divisas, atraído por una política monetaria que alentaba la especulación financiera. Para eso, la actual gestión resolvió con rapidez el litigio con los fondos buitres gracias a una oferta generosa, que reconoció todos sus reclamos (incluido el pago de las costas legales) con un descuento del $25 \%$. Desde entonces, la nación, provincias y empresas encararon un programa de endeudamiento inédito por su magnitud y variedad de activos emitidos.

El giro también se notó en un retroceso hacia una posición de más respeto al statu quo financiero internacional. Al virtual abandono del debate en la ONU por la difusión de los principios de restructuración de deuda soberana se suman, de un lado, un repliegue en la participación en estrategias de financiamiento regional como el Banco del Sur; y de otro, el privilegio de las plazas y bancos estadounidenses e ingleses como espacios y acreedores privilegiados, respectivamente. Cabe señalar que la creciente importancia de China como potencia global y socio local limitó la intención inicial de recortar los proyectos de financiamiento acordados en la gestión anterior. Con todo, el giro reciente en la inserción financiera generó un retroceso en términos de autonomía y profundizó la dependencia.

\section{BIBLIOGRAFÍA}

Abeles, Martín y Kiper, Esteban (2010). El G20 y el rol de la Argentina. En: Serie Aportes, Documento n. ${ }^{\circ}$ 2, Cepes, AEDA, Fundación Friedrich Ebert.

Actis, E.; Calderón, E.; Lorenzini, M. y Zelicovich, J. (2016). La Política exterior del kirchnerismo a la luz del modelo de desarrollo y la estrategia de inserción, p. 189-233. En: Busso, Anabella (Coord.). Modelos de desarrollo e integración internacional: aportes para el análisis 
de la política exterior argentina desde la redemocratización 1983-2011, Tomo I. Rosario: UNR Editora.

Alonso, J. (2016). Las crisis de deuda soberana de la República Argentina en el periodo democrático. La (des)inserción financiera internacional como condicionante de los modelos de desarrollo y la política exterior (1983-2011), p. 164-192. En: Busso, A. (Coord.) Modelos de desarrollo e inserción internacional. Aportes para el análisis de la política exterior argentina desde la redemocratización 1983-2011, Tomo II. Rosario: UNR Editora.

Ámbito Financiero (2010, 8 de febrero). El dibujo de la inflación trajo ahorro por más de \$70.000 M.

Aronskind, R. (2015). Intuiciones y confrontaciones. Para pensar la política económica kirchnerista. En: Márgenes. Revista de Economía Política, Año 1, n. 1, p. 15-32.

Bembi, Mariela y Nemiña, Pablo (2007). Neoliberalismo y desendeudamiento. La relación Argentina - FMI. Buenos Aires: Capital Intelectual.

Bohoslavsky, Juan Pablo (s. f.). Matices y derivaciones jurídicas del pago al FMI. Mimeografiado.

Bordón, Marisa (2017). El Estado y el capital financiero en Argentina entre 2002 y 2012. La deuda pública. En: Problemas del Desarrollo. Revista Latinoamericana de Economía, Vol. 48, n. 190, p. $83-108$.

Bresser Pereira, Luis (2007). Estado y mercado en el nuevo desarrollismo. En: Nueva Sociedad, n. 210 , p. 110125.

Burín, Gabriel (2005). El cambio en la Política Financiera Internacional de EE. UU. para Argentina en la Crisis del 2001. Disertación de Maestría, Relaciones Internacionales, Flacso Argentina.

Busso, Anabella (2014). Los vaivenes de la política exterior argentina re-democratizada (1983-2013). Reflexiones sobre el impacto de los condicionantes internos. En: Estudios Internacionales, n. ${ }^{\circ}$ 177, p. 9-33.

Campos, Segundo (2008). El bono vinculado al PIB: la desagradable progresión geométrica de una buena idea. En: Lectura, n. ${ }^{\circ} 33$, Iniciativa para la Transparencia Financiera, disponible en http://www.itf.org.ar/.

Cantamutto, Francisco y Ozarow, Daniel (2016). Serial Payers, Serial Losers? The Political Economy of Argentina's Public Debt, p. 123-147. En: Economy and Society, Vol. 45, n. ${ }^{\circ} 1$.

Castiglioni, Lucas (2013). La nueva arquitectura financiera regional. Documento de Trabajo. Buenos Aires: Clacso.

Cenda (2010). La Macroeconomía después de la convertibilidad, p. 7-46. En: Cenda, La anatomía del nuevo patrón de crecimiento y la encrucijada actual. La economía argentina en la post-Convertibilidad (2002-2010). Buenos Aires: Cara o ceca.

Chesnais, François (2001). La mundialización financiera. Buenos Aires: Losada.

Cifra (2009). La evolución del Sistema Previsional Argentino. En: Documento de Trabajo, n. 2.

Clemente, Dario (2017). El regionalismo post-hegemónico hoy: ¿un aporte sudamericano a la teoría de las RR. II. globales? Ponencia presentada en las V Jornadas de Relaciones Internacionales, Flacso, Buenos Aires, 2-3 de noviembre. 
En búsqueda de una inserción financiera poshegemónica. La políica financiera externa del kirchnerismo

Cruces, Juan y Levy Yeyati, Eduardo (2016). Enseñanzas para el mundo del problema entre Argentina y los holdouts. En: Foco Económico.

Cruces, Juan y Trebesch, Cristoph (2013). Sovereign Defaults: The Price of Haircuts, p. 85-117. En: American Economic Journal: Macroeconomics, Vol. 5, n. ${ }^{\circ} 3$.

Damill, Mario y Frenkel, Roberto (2013). La economía argentina bajo los Kirchner: una historia de dos lustros. En: Documentos Técnicos, ITF, n. ${ }^{\circ} 91$.

Damill, Mario, Frenkel, Roberto y Rapetti, Martín (2005). La deuda argentina: historia, default y reestructuración, p. 187-233. En: Desarrollo Económico, Vol. 45, n.º 178.

Espert, J. (2017) La Argentina Devorada, Buenos Aires: Galerna.

Feibelman, Adam (2017). Ecuador's 2008-2009 Debt Restructuring, p. 48-64. En: Bohoslavsky, Juan Pablo y Raffer, Kunibert (Eds.). Sovereign Debt Crises. What Have We Learned? Cambridge: Cambridge University Press.

Fernández, Víctor, Lauxmann, Carolina y Trevignani, Manuel (2014). Emergencia del Sur Global. Perspectivas para el desarrollo de la periferia latinoamericana. En: Economia e Sociedade, Vol. 23, n. ${ }^{\circ}$ 3, p. 611-643.

Gaggero, Alejandro, Gaggero, Jorge y Rúa, Magdalena (2015). Principales características e impacto macroeconómico de la fuga de capitales en Argentina. En: Problemas del Desarrollo. Revista Latinoamericana de Economía, Vol. 46, n.ำ 182, p. 67-90.

Gaggero, Alejandro, Schorr, Martín y Wainer, Andrés (2014). Restricción eterna: el poder económico durante el kirchnerismo. Buenos Aires: Futuro Anterior Ediciones.

Gezmiş, Hilal (2017). From Neoliberalism to Neo-developmentalism? The Political Economy of Post-crisis Argentina (2002-2015). En: New Political Economy, Vol. 23, n.ํㅜ 1, p-. 66-87.

Giuliano, Héctor (2015). La deuda bajo la administración Kirchner. En: Cuadernos de Economía Crítica, Vol. 1, n. ${ }^{\circ}$ 2, p. 153-159.

Guzmán, Martín (2016). An Analysis of Argentina's 2001 Default Resolution. En: CIGI Papers, n. ${ }^{\circ} 110$.

IMF -International Monetary Fund- (2017). Gross domestic product, current prices (U.S. dollars), En: World Economic Outlook Database, octubre.

Indec -Instituto Nacional de Estadística y Censos de la República Argentina- (2018). Estadísticas integradas de Balanza de pagos, Posición de inversión internacional y Deuda externa.

Infobae (2013, 5 de marzo). Chávez aportó a la Argentina U\$ 5.500 millones.

Katz, Claudio (2015). ¿Qué es el neodesarrollismo? Una visión crítica. Argentina y Brasil. En: Serviço Social \& Sociedade, n. ${ }^{\circ}$ 122, p. 224-249.

Kern, Alejandra y Nemiña, Pablo (2017). La relación entre la Argentina y el FMI en el marco de las transformaciones del orden internacional. Difusión del poder y nuevas alianzas en política exterior. En: Pucciarelli, A. y Castellani, A. (Coords.). Los años del kirchnerismo. La disputa hegemónica tras la crisis del orden neoliberal (p. 241 -265). Buenos Aires: Siglo XXI.

Kulfas, Matías (2016). Los tres kirchnerismos. Una historia de la economía argentina, 2003-2015. Buenos Aires: Siglo XXI. 
Kulfas, Matías y Schorr, Martín (2003). La deuda externa argentina. Diagnóstico y lineamientos propositivos para su reestructuración. Argentina: Fundación OSDE/CIEPP.

Lo Vuolo, Rubén y Seppi, Fernando (2008). La falacia del desendeudamiento del sector público argentino. Documento de trabajo n..$^{\circ}$ 61. Buenos Aires: CIEPP.

Manzo, Alejandro (2017). Reestructuraciones de deuda soberana: El debate sobre su regulación en términos de disputa por la gobernanza global. En: Revista Direito e Praxis, en prensa.

Ministerio de Finanzas, Secretaría de Finanzas, Oficina Nacional de Crédito Público (s. f.). Información de la Deuda Pública, varios años.

Ministerio de Hacienda (2018). Finanzas Públicas, Sector Público Nacional, base caja, en: Portal de Datos Económicos.

Müller, Alberto (2013). Default y reestructuración: ¿Cuál fue la real quita de la deuda pública argentina? En: Documento de Trabajo, n. ${ }^{\circ}$ 32, Cespa - FCE - UBA, marzo, p. 47.

Nemiña, Pablo (2011). Estrategias de negociación del FMI y la Argentina durante el periodo 2003 - 2004. En: Temas y Debates, Año 15, n.2 22, p. 87-113.

Nemiña, Pablo y Larralde, Juan (2018). Etapas históricas de la relación entre el Fondo Monetario Internacional y América Latina (1944-2015). En: América Latina en la Historia Económica, Vol. 25, n. ${ }^{\circ}$, p. 275-313.

Ocampo, Juan Antonio (2011). ¿Cómo fue el desempeño de América Latina durante la crisis financiera global?. En: Ensayos Económicos, n. ${ }^{\circ} 61 / 62$, p. 7-33.

Ortiz, Isabel y Ugarteche, Oscar (2009). Banco del Sur: avances y desafíos. En: Comercio Exterior, Vol. 59, n. ${ }^{\circ}$, p. $391-400$.

Oviedo, Eduardo (2015). El ascenso de China y sus efectos en la relación con Argentina. En: Estudios Internacionales, n. ${ }^{\circ} 180$, p. 67-90.

Peralta Ramos, Mónica (2007). La economía política argentina: Poder y clases sociales, 1930-2006. Buenos Aires: Fondo de Cultura Económica.

Porta, Fernando, Santarcángelo, Juan y Schteingart, Daniel (2017). Un proyecto político con objetivos económicos. Los límites de la estrategia kirchnerista. En: Pucciarelli, A. y Castellani, A. (Coords.). Los años del kirchnerismo. La disputa hegemónica tras la crisis del orden neoliberal, Buenos Aires: Siglo XXI.

Kulfas, Matías (2016). Los tres kirchnerismos. Una historia de la economía argentina, 2003-2015. Buenos Aires: Siglo XXI, 240p.

Riggirozzi, Pía y Tussie, Diana (2012). The Rise of Post-Hegemonic Regionalism in Latin America. En: Riggirozzi, P. y Tussie, D. (Eds.). The Rise of Post-Hegemonic Regionalism. The Case of Latin America (p. 1-16). Dordrecht: Springer, 194p.

Riggirozzi, Pía y Tussie, Diana (2017). Rethinking our Region in a Post-Hegemonic Moment. En: Briceño-Ruiz J. y Morales, I. (Eds.). Post-Hegemonic Regionalism in the Americas. Toward a Pacific-Atlantic Divide? (p. 16-31). London: Routledge, 204p. 
Simonoff, Alejandro (2009). Regularidades de la Política Exterior de Néstor Kirchner. En: CONfines de Relaciones Internacionales y Ciencia Política, Vol. 5, n.ํ10, p. 71-86.

Svampa, Maristella (2012). Consenso de los Commodities, Giro Ecoterritorial y Pensamiento crítico en América Latina. En: Revista del Observatorio Social de América Latina, Año XIII, n. 32 , p. 15-38.

Trucco, Pablo (2012). The Rise of Monetary Agreements in South America. En: Riggirozzi, Pia (Ed.). The Rise of Post-Hegemonic Regionalism. The Case of Latin America, p.101-124. Dordrecht: Springer. CIUDAD DE EDICIÓN: EDITORIAL.

Vadell, Javier, Brandão, Roberto y Rojas, Gustavo (2016). China y la nueva ofensiva financiera en América Latina. Los acuerdos con Argentina. En: Lechini, Gladys y Giaccaglia, Clarisa (Eds.). Poderes emergentes y Cooperación Sur-Sur: perspectivas desde el Sur Global (p. 175-192). Rosario: UNR Editora.

Val, María (2017). La reestructuración de la deuda pública argentina. Un análisis de las estrategias de negociación durante el gobierno de Néstor Kirchner. Ponencia presentada en las V Jornadas de Relaciones Internacionales, Flacso, Buenos Aires, 2-3 de noviembre.

Varesi, Gastón (2011). Argentina 2002-2011: neodesarrollismo y radicalización progresista. En: Realidad Económica, n. ${ }^{\circ} 264$, p. 33-59. 